\title{
SARS-CoV-2 pneumonia succesfully treated with cpap and cycles of tripod position: a case report
}

\author{
Michela Rauseo, Lucia Mirabella, Rosa Roberta Caporusso, Leonarda Pia Cantatore, Marco Paolo Perrini, \\ Paolo Vetuschi, Daniela La Bella, Livio Tullo and Gilda Cinnella* (i)
}

\begin{abstract}
Background: Pneumonia induced by 2019 Coronavirus (COVID-19) is characterized by hypoxemic respiratory failure that may present with a broad spectrum of clinical phenotypes. At the beginning, patients may have normal lung compliance and be responsive to noninvasive ventilatory support, such as CPAP. However, the transition to more severe respiratory failure - Severe Acute Respiratory Syndrome (SARS-CoV-2), necessitating invasive ventilation is often abrupt and characterized by a severe V/Q mismatch that require cycles of prone positioning. The aim of this case is to report the effect on gas exchange, respiratory mechanics and hemodynamics of tripod (or orthopneic sitting position) used as an alternative to prone position in a patient with mild SARS-CoV-2 pneumonia ventilated with helmet CPAP.
\end{abstract}

Case presentation: A 77-year-old awake and collaborating male patient with mild SARS-CoV-2 pneumonia and ventilated with Helmet CPAP, showed sudden worsening of gas exchange without dyspnea. After an unsuccessful attempt of prone positioning, we alternated three-hours cycles of semi-recumbent and tripod position, still keeping him in CPAP. Arterial blood gases (PaO2/FiO2, $\mathrm{PaO} 2, \mathrm{SaO} 2, \mathrm{PaCO} 2$ and $\mathrm{A}$ a gradient), respiratory (VE, VT, RR) and hemodynamic parameters (HR, MAP) were collected in the supine and tripod position. Cycles of tripod position were continued for 3 days. The patient had a clinically important improvement in arterial blood gases and respiratory parameters, with stable hemodynamic and was successfully weaned and discharged to ward 10 days after pneumonia onset.

Conclusions: Tripod position during Helmet CPAP can be applied safely in patients with mild SARS-CoV-2 pneumonia, with improvement of oxygenation and V/Q matching, thus reducing the need for intubation.

Keywords: COVID-19, SARS-CoV-2 pneumonia, Helmet CPAP, Tripod position

\section{Background}

Hypoxemic respiratory failure is the characteristic aspect for presentation of pneumonia induced by 2019 Coronavirus (COVID-19). SARS-CoV-2 patients present with a wide spectrum of clinical severity, ranging from asymptomatic to pneumonia to ARDS-like phenotypes [1,2]. In the making of more robust evidence, widely shared

\footnotetext{
*Correspondence: gilda.cinnella@unifg.i

Department of Anesthesia and Intensive Care Unit, Università degli Studi di Foggia, Azienda Ospedaliero Universitaria "Ospedali Riuniti di Foggia", Viale Pinto, 1, 71122 Foggia, Italy
}

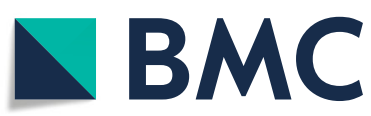

(c) The Author(s). 2021 Open Access This article is licensed under a Creative Commons Attribution 4.0 International License, which permits use, sharing, adaptation, distribution and reproduction in any medium or format, as long as you give appropriate credit to the original author(s) and the source, provide a link to the Creative Commons licence, and indicate if changes were made. The images or other third party material in this article are included in the article's Creative Commons licence, unless indicated otherwise in a credit line to the material. If material is not included in the article's Creative Commons licence and your intended use is not permitted by statutory regulation or exceeds the permitted use, you will need to obtain permission directly from the copyright holder. To view a copy of this licence, visit http://creativecommons.org/licenses/by/4.0/ The Creative Commons Public Domain Dedication waiver (http://creativecommons.org/publicdomain/zero/1.0/) applies to the data made available in this article, unless otherwise stated in a credit line to the data. hypothesis suggests that together with viral load and patient's physiological reserve, the activation's amplitude of two biological cascades, the interleukin 6 (IL-6) cytokine storm [3] and the disseminated intravascular cascade (DIC) [4], are responsible for the inflammatory host response in the lungs.

At the beginning, patients may have normal lung compliance and be responsive to noninvasive ventilatory support, such as CPAP. However, the transition to more severe respiratory failure - Severe Acute Respiratory Syndrome (SARS-CoV-2), necessitating invasive 
ventilation is often abrupt and characterized by a severe $\mathrm{V} / \mathrm{Q}$ mismatch that require cycles of prone positioning $[2,5]$.

We report on the clinical course of a patient suffering from refractory hypoxemia due to COVID-19 pneumonia treated with CPAP and helmet interface in the out of bed tripod position (Fig. 1). We choose this solution, since the patient was well adapted to CPAP, but did not tolerate other facial interfaces nor prone position. Repeated shifting from supine to tripod determined a stable improvement of ventilation to perfusion (V/Q) matching and $\mathrm{PaO} 2 / \mathrm{FiO} 2$ ratio and prevented intubation and invasive mechanical ventilation.

\section{Case presentation}

A 77-year-old man was admitted to the emergency department (ER), on March 6th. His symptoms commenced on the previous day, while at home, with sore throat, dry cough, mild dyspnea and subjective fevers. He had been in contact in earlier days with an individual positive for COVID-19 disease, and was otherwise healthy. Physical examination revealed a temperature of $37^{\circ} \mathrm{C}$, pulse rate of 80 beat $/ \mathrm{min}$, mean blood pressure $(\mathrm{mBP}) 80 \mathrm{mmHg}$, respiratory rate (RR) 18 breath/min and oxygen saturation $87 \%$ in room air. SARS-CoV-2 was detected in a nasopharyngeal swab specimen by real-time reverse-transcriptase PCR. After having unsuccessfully been treated for $24 \mathrm{~h}$ with Venturi Mask Oxygen in the Infectious Diseases department, the patient was referred to our ICU and CPAP with helmet immediately started.

At ICU admission he had no fever, WBC $4.35^{*} 10^{3}$ $\mathrm{mcL}$ and CRP of $120 \mathrm{mg} / \mathrm{L}$. Chest X ray showed interstitial lung infiltrates, no sign of fatigue nor tachypnea.

On admission CPAP was set at $10 \mathrm{cmH}_{2} \mathrm{O}$ with a $\mathrm{FiO}_{2}$ of $50 \%$, in order to reach a VT of $6-7 \mathrm{ml} / \mathrm{Kg} \mathrm{PBW}$. Under such setting, the highest $\mathrm{PaO} 2 / \mathrm{FiO} 2$ was 172 , PaCO2 34 mmHg, pH 7.34, RR 20. On march 8th, PaO2/

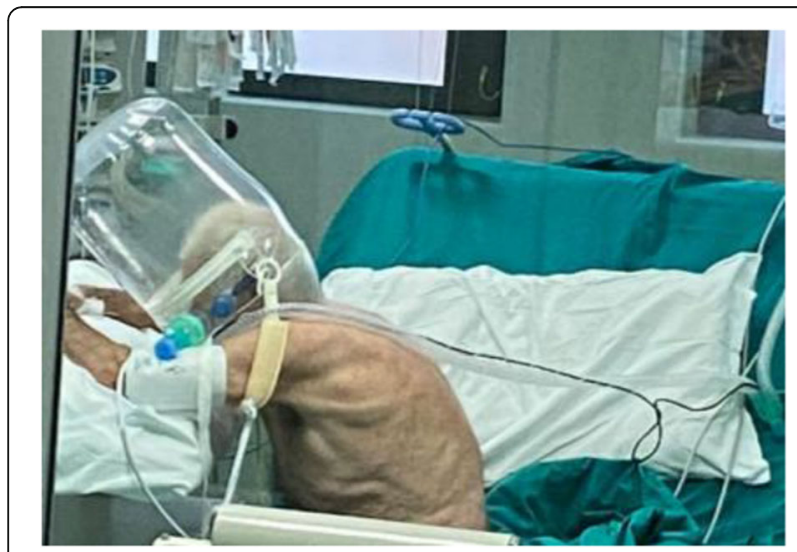

Fig. 1 Patient in tripod position during Helmet CPAP
FiO2 decreased to 136 and CPAP was increased to 12 $\mathrm{cmH} 2 \mathrm{O}$, with $\mathrm{FiO} 255 \% . \mathrm{PaO} 2 / \mathrm{FiO} 2$ further decreased and helmet was then temporarily substituted with a full face mask in order to position him prone. However, both face mask and prone position were not tolerated. The patient was awake and responsive, and in a last attempt to avoid intubation he was asked to assume an orthopneic (or tripod) position (Fig. 1). Rapidly, after the assumption of tripod position $\mathrm{SaO} 2$ improved and patient was kept in the same position with CPAP $10 \mathrm{cmH} 2 \mathrm{O}$ and $\mathrm{FiO} 255 \%$. The $\mathrm{PaO} 2 / \mathrm{FiO} 2$ ratio increased from 136 to $196(p<.05)$ after $3 \mathrm{~h}$ and $\mathrm{PaO} 2 / \mathrm{PAO} 2$ went from 0.22 to 0.34 , showing an actual recovery in terms of $\mathrm{O} 2$ effective delivery (Fig. 2). The respiratory rate decreased from 20 to 17 (Table 1) and we were able to lower CPAP to $8 \mathrm{cmH} 2 \mathrm{O}$ and $\mathrm{FiO} 2$ to $40 \%$, without changes in $\mathrm{SaO} 2$ or hemodynamics. The patient felt more comfortable and able to take some rest in that position compared to the supine position. We continued alternating cycles of tripod and semirecumbent positions for the following 4 days (Fig. 2). Eight days after ICU admission, he was weaned successfully to a conventional O2 Ventimask. SARS-CoV-2 was detected in nasopharyngeal swab specimen until March 28th. On day 10, with a resolution of the pneumonia, he was sent back to a post-COVID ward isolation and then discharged home.

\section{Discussion and conclusions}

To our knowledge this is the first report of refractory hypoxemia successfully treated with CPAP with helmet and cycles of tripod position. Moreover, this case novelty in our opinion lies also on the peculiar pathology treated, i.e. SARS-CoV-2 pneumonia.

Patients requiring hospitalization usually have hypoxemia due to increased lung permeability, loss of perfusion's regulation with hyper-perfusion of inflamed lung areas and significant ventilation to perfusion $(\mathrm{V} / \mathrm{Q})$ mismatch due to shunt effect, more than to atelectasis $[2$, 5].

At the beginning, hypoxemia may be compensated by an increase in minute ventilation without marked dyspnea. To some extent in such cases the inspiratory effort is not disproportionate and work of breathing (WOB) tolerable. At this stage, patients are responsive to an increase in $\mathrm{FiO}_{2}$ and to non-invasive ventilation approaches, such as Continuous Positive Airways Pressure (CPAP), aimed at maintaining alveolar patency and improving V/Q matching. However, the transition to more severe clinical patterns of acute respiratory failure is often very rapid. When hypoxemia persist or worsen, the inspiratory load may become excessive, generating too negative swings of intrathoracic pressure and further lung injury [6-8]. Under such conditions intubation should not be delayed. Clinicians have thus barely a very 

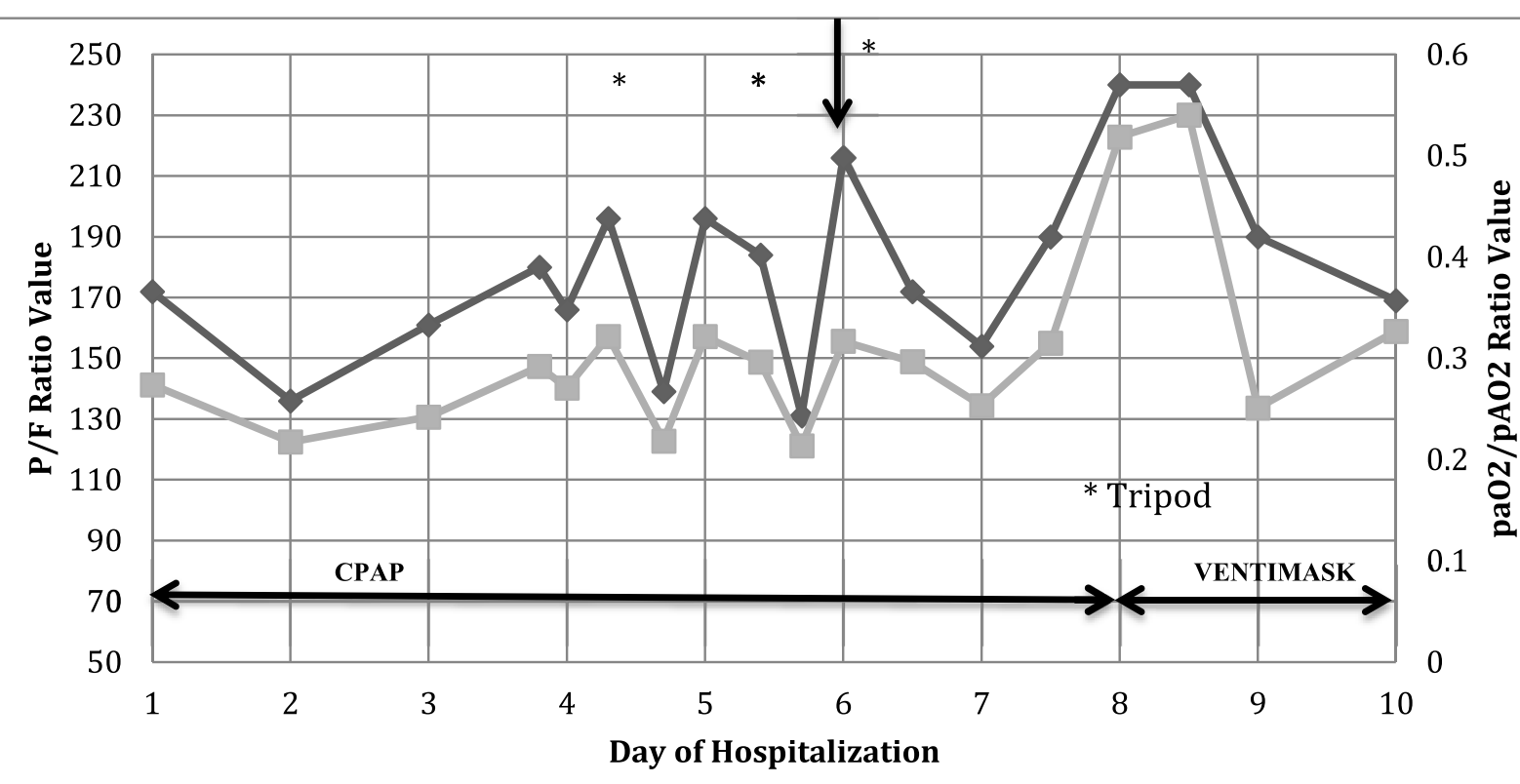

0.1

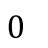

$\leadsto$ P/F Ratio $\quad-$ pa02/pA02 Ratio

Fig. 2 Time course of recorded P/F ratio and paO2/pAO2 ratio during CPAP with alternating cycles of semirecumbent and tripod position. The worst data recorded daily are reported

narrow windows to profit of before shifting to invasive mechanical ventilation when patients are unresponsive to non-invasive approaches.

Hence, changing patients' position can allow for taking advantage of this "no man's land" to obtain pulmonary blood flow redistribution, better V/Q matching and increased $\mathrm{PaO} 2 / \mathrm{FiO} 2$ ratio.

Actually, body position is not a neutral aspect of patients' care, as evidenced by an amount of physiological, experimental and clinical studies in different surgical and ICU settings $[9,10]$. The modification in position

Table 1 Respiratory mechanics and hemodynamics in both positions

\begin{tabular}{llll}
\hline & Supine & Tripod & $\boldsymbol{p}$ value \\
\hline PEEP $(\mathrm{cmH} 2 \mathrm{O})$ & 10 & 10 & $=1$ \\
$\mathrm{SaO} 2(\%)$ & 93 & 99 & $<0.05$ \\
$\mathrm{VT}(\mathrm{ml})$ & 370 & 420 & $<0.05$ \\
$\mathrm{VE}(\mathrm{L} / \mathrm{min})$ & 5.6 & 7.2 & $=0.2$ \\
$\mathrm{RR}(\mathrm{bpm})$ & 20 & 17 & $=0.14$ \\
$\mathrm{PaO} 2 / \mathrm{FiO} 2$ & 136 & 196 & $<0.05$ \\
$\mathrm{FiO} 2(\%)$ & 50 & 50 & $=1$ \\
$\mathrm{~A}-\mathrm{a}(\mathrm{O} 2)(\mathrm{mmHg})$ & 244 & 232 & $<0.05$ \\
$\mathrm{PaO} 2 / \mathrm{PAO} 2$ & 0.22 & 0.34 & $=0.89$ \\
$\mathrm{mBP}(\mathrm{mmHg})$ & 90 & 80 & $=0.4$ \\
$\mathrm{HR}(\mathrm{bpm})$ & 60 & 60 & $=1$ \\
\hline
\end{tabular}

can affect respiratory mechanics by changing resistance and/or compliance of the respiratory system and its lung and chest wall components, and by changing static lung volume and its regional distribution. Mechanical ventilation, either invasive or non-invasive, is commonly delivered in a semi-recumbent supine position, that offer the advantage of increased Functional Residual Capacity (FRC), reduced airways resistance and $\mathrm{WOB}$ and improved oxygenation versus the supine [11, 12]. Prone positioning (PP) classically is being used in severe respiratory failure to reopen collapsed lung areas, obtain a more even tidal volume distribution together with a redistribution of pulmonary blood flow [10-12], while in SARS-COV-2, PP is indicated mainly because of its effects on blood flow [2, 6-8].

Under such conditions, the orthopneic or tripod position is a middle way. This posture is often assumed instinctively by individuals experiencing shortness of breath and used in dyspneic patients that sit and lean forward with hands on their knees or on the side of the bed with an over bed table in front to lean on and several pillows on the table to rest on. Patients experience subjective relief of dyspnea, while diaphragmatic function and thoraco-abdominal movements are improved, thus allowing a better V/Q matching [9-14], as in the present case. Recently, Ding et al. [15] reported the first cases of mild ARDS under non-invasive ventilation successfully treated with PP, without need for intubation. 
We here suggest that in patients not tolerating to be prone, an alternative may be to keep them in tripod.

In conclusion, to our knowledge, this is the first case that report successful treatment of mild respiratory failure with cycles of tripod position. Although more data are needed to draw definite deductions, this case suggest that in selected SARS-COV-2 patients, a better pulmonary blood flow distribution with improved V/Q matching can be obtained by shifting them in this position, thus avoiding the need for intubation and fasten recovery. We are aware that this represents a single success, thus providing only little evidence on safety and efficacy. But, compared to the risk related to intubation or prone position failure, in this single case, this position, associated to Helmet CPAP, has represented a valid alternative strategy.

\section{Abbreviations}

COVID- 19: Coronavirus 2019; SARS-CoV-2: Severe Acute Respiratory Syndrome Coronavirus-2; CPAP: Continuous Positive Airways Pressure; PEEP: Positive End Expiratory Pressure; VE: Minute Ventilation; VT: Tidal Volume; RR: Respiratory Rate; V/Q: Ventilation to Perfusion Matching; mBP: Mean Blood pressure; HR: Heart Rate; FiO2: Fraction of Inspired Oxygen; SaO2: Oxygen Saturation; PaO2: Partial Pressure of Oxygen in Arterial Blood; PaCO2: Partial Pressure of Carbon Dioxide in Arterial Blood; PAO2: Partial Pressure of Oxygen in the Alveolar Gas; WBC: White Blood Count; CRP: C Reactive Protein; DIC: Disseminated Intravascular Cascade; IL-6: Interleukin-6; WOB: Work Of Breathing; FRC: Functional Residual Capacity; PP: Prone Positioning; ARDS: Acute Respiratory; ICU: Intensive Care Unit

\section{Acknowledgements}

We want to thank all the great healthcare professionals involved in the ICU COVID-19 Department of "Ospedali Riuniti di Foggia" during this huge emergency.

\section{Authors' contributions}

MR wrote the first draft and designed the work, LM and GC revised the last version. RRC, LPC, MPP, PV, DLB and LT have made substantial contributions to the conception of the manuscript. All authors have read and approved the manuscript and have agreed both to be personally accountable for the author's own contributions and to ensure that questions related to the accuracy or integrity of any part of the work, even ones in which the author was not personally involved, are appropriately investigated, resolved, and the resolution documented in the literature.

\section{Funding}

No founding were received.

\section{Availability of data and materials}

Data supporting our findings can be found at gilda.cinnella@unifg.it, the corresponding author.

\section{Ethics approval and consent to participate}

Not Applicable.

\section{Consent for publication}

The patient gave written consent for his personal and clinical details along with any identifying images to be published in this study.

\section{Competing interests}

Authors declare no competing interests.
Received: 7 June 2020 Accepted: 16 December 2020

Published online: 08 January 2021

\section{References}

1. Rello J, Storti E, Belliato M, Serrano R. Clinical phenotypes of SARS-CoV-2: Implications for clinicians and researchers. Eur Respir J. 2020:2001028. https://doi.org/10.1183/13993003.01028-2020.

2. Marini JJ, Gattinoni L. Management of COVID-19 respiratory distress. JAMA. Published online April 24. 2020. https://doi.org/10.1001/jama.2020.6825.

3. Huang C, Wang Y, Li X, Ren L, Zhao J, Hu Y. Clinical features of patients infected with 2019 novel coronavirus in Wuhan, China. Lancet. 2020;395: 497-506 10.1016/S0140-736(20)30183.

4. Tang N, Li D, Wang X, Sun Z. Abnormal coagulation parameters are associated with poor prognosis in patients with novel coronavirus pneumonia. J Thromb Haemost. 2020. [e-pub]. https://doi.org/10.1111/jth. 14768 .

5. Matricardi P, Dal Negro R, Nisini R. The first, comprehensive immunological model of COVID-19: implications for prevention, diagnosis, and public health measures. Preprints. 2020;31(5):454-70.

6. Telias I, Katira BH, Brochard L. Is the prone position helpful during spontaneous breathing in patients with COVID-19? JAMA Published online May. 2020;15. https://doi.org/10.1001/jama.2020.8539.

7. Brochard L, Slutsky A, Pesenti A. Mechanical ventilation to minimize progression of lung injury in acute respiratory failure. Am J Respir Crit Care Med. 2017;195(4):438-42. https://doi.org/10.1164/rccm.201605-1081CP.

8. Elharrar $X$, Trigui $Y$, Dols A, et al. Use of prone positioning in nonintubated patients with COVID-19 and hypoxemic acute respiratory failure. JAMA. Published online May 15. 2020. https://doi.org/10.1001/jama.2020.8255.

9. O'Neill S, McCarthy DS. Postural relief of dyspnoea in severe chronic airflow limitation: relationship to respiratory muscle strength. Thorax. 1983;38:595600.

10. Lumb AB, Nunn JF. Respiratory function and ribcage contribution to ventilation in body positions commonly used during anesthesia. Anesth Analg. 1991;73:422-6.

11. Guerin C, Reignier J, Richard JC, et al. Prone positioning in severe acute respiratory distress syndrome. N Engl J Med. 2013;368:2159-68.

12. Milic-Emili J, Henderson JA, Dolovich MB, et al. Regional distribution of inspired gas in the lung. J Appl Physiol. 1966;21:749-59.

13. Albert RK, Hubmayr RD. The prone position eliminates compression of the lungs by the heart. Am J Respir Crit Care Med. 2000;161:1660-5.

14. Gattinoni L, Pesenti A, Carlesso E. Body position changes redistribute lung computed-tomographic density in patients with acute respiratory failure: impact and clinical fallout through the following 20 years. Intensive Care Med. 2013;39:1909-15.

15. Ding $L$, Wang $L, M a W$, et al. Efficacy and safety of early prone positioning combined with HFNC or NIV in moderate to severe ARDS: a multi-center prospective cohort study. Crit Care. 2020;24:28. https://doi.org/10.1186/ s13054-020-2738-5.

\section{Publisher's Note}

Springer Nature remains neutral with regard to jurisdictional claims in published maps and institutional affiliations.
Ready to submit your research? Choose BMC and benefit from:
- fast, convenient online submission
- thorough peer review by experienced researchers in your field
- rapid publication on acceptance
- support for research data, including large and complex data types
- gold Open Access which fosters wider collaboration and increased citations
- maximum visibility for your research: over $100 \mathrm{M}$ website views per year
At BMC, research is always in progress.
Learn more biomedcentral.com/submissions 